\title{
Sniff nasal inspiratory pressure in children with muscular, chest wall or lung disease
}

\author{
B. Fauroux ${ }^{\star, \#}$, G. Aubertin*, E. Cohen ${ }^{\star, \#}$, A. Clément*,\# and F. Lofaso ${ }^{\star \uparrow,+}$
}

\section{ABSTRACT: Sniff nasal inspiratory pressure is proposed as a noninvasive test of inspiratory muscle strength. During this manoeuvre, the nasal pressure is supposed to reflect oesophageal pressure.}

The aim of the present study was to compare the nasal pressure with the oesophageal pressure during a maximal sniff in children with neuromuscular disease $(N M, n=78)$, thoracic scoliosis $(n=12)$ and cystic fibrosis $(C F, n=23)$.

A significant correlation was observed between the sniff nasal and oesophageal pressure. The ratio of the sniff nasal/oesophageal pressure was lower in patients with CF $(0.72 \pm 0.13)$ than in NM patients $(0.83 \pm 0.17)$ or patients with thoracic scoliosis $(0.86 \pm 0.10)$. In patients with CF and NM disease, this ratio was not correlated to age or spirometric data. The difference between the sniff oesophageal and nasal pressure exceeded $15 \mathrm{cmH}_{2} \mathrm{O}$ in 17, 33 and $87 \%$ of the $\mathrm{NM}$, thoracic scoliosis and CF patients, respectively.

Sniff nasal pressure often underestimates the strength of inspiratory muscles in cystic fibrosis. Such an underestimation occurs more rarely in neuromuscular disease disorders and thoracic scoliosis. A normal value excludes inspiratory muscle weakness but a low value requires the measurement of the oesophageal pressure.

KEYWORDS: Cystic fibrosis, nasal pressure, neuromuscular disease, oesophageal pressure, respiratory muscles

lassically, the strength of the inspiratory muscles is assessed noninvasively by the pressure measured at the mouth and sustained for $\geqslant 1 \mathrm{~s}$ during a maximal inspiratory pressure $(P \mathrm{I}, \max )$ performed against an occlusion [1, 2]. It is generally assumed that if three equal maximal efforts are obtained, then the subject is supposed to have reached a maximal effort. But it has been shown that reproducibility does not ensure maximality [3]. Since PI,max is not easy to perform, the results are prone to important variations and low results may reflect not only inspiratory muscle weakness, but also a lack of motivation and/or coordination of the patient. Moreover, many other factors such as a training effect, chest wall configuration and stabilisation during the manoeuvres may contribute to the range of pressures observed in normal children [4-6].

As sniff is a natural manoeuvre that many children find easier to perform than static efforts, sniff nasal inspiratory pressure (SNIP) has been proposed as an alternative, or complementary, test to PI,max [7-10]. The SNIP manoeuvre consists of measuring nasal pressure in an occluded nostril during a maximal sniff performed through the controlateral nostril from functional residual capacity [11]. Transmission of the oesophageal pressure during a maximal sniff manoeuvre (Poes) to the nose is obtained, considering that a trans-nasal pressure of 10 $15 \mathrm{cmH}_{2} \mathrm{O}$ is necessary to obtain a collapse of the unplugged nostril valve in adults [12]. Normal values for the SNIP have been established for children as for adults [7-10]. Values in healthy children aged 6-17 yrs are similar to those measured in adults, with an SNIP of 99$117 \mathrm{cmH}_{2} \mathrm{O}$ in young males and $92-97 \mathrm{cmH}_{2} \mathrm{O}$ in young females [8]. SNIP correlates with age and weight [8]. The main advantage of the SNIP manoeuvre is that it is a more pleasant technique than PI,max for most subjects and requires little practice. It solves the leak problems, which are sometimes observed with a mouthpiece in neuromuscular patients $[11,13]$. It also reduces the risk of fatigue because the manoeuvre is natural, easy and shorter than PI,max, which requires a sustained peak pressure of $\geqslant 1 \mathrm{~s}$.

\section{AFFILIATIONS}

*Paediatric Pulmonary Dept, AP-HP, Hôpital Armand Trousseau,

\#INSERM UMR S-893, Université Pierre et Marie Curie, Paris,

'Dept of Clinical Physiology, AP-HP, Hôpital Raymond Poincaré,

Université de Versailles Saint Quentin en Yvelines, Garches, and +INSERM U 851, Créteil, France.

CORRESPONDENCE

B. Fauroux

Paediatric Pulmonary Dept AP-HP

Hôpital Armand Trousseau

Research Unit INSERM UMR S-893 Equipe 12

Université Pierre et Marie CurieParis 6

28 avenue du Docteur Arnold Netter Paris

F-75012 France

Fax: 33144736174

E-mail: brigitte.fauroux@trs.aphp.fr

Received:

April 022008

Accepted after revision:

September 012008

\section{SUPPORT STATEMENT}

B. Fauroux was supported by the Association Française contre les Myopathies, Assistance PubliqueHôpitaux de Paris, INSERM, Legs Poix and Université Pierre et Marie Curie-Paris 6.

\section{STATEMENT OF INTEREST}

None declared 
A limitation of the SNIP manoeuvre is that it may underestimate Poes in subjects with nasal obstruction, significant lung or airway disease [14], as well as in severe neuromuscular patients considering that a trans-nasal pressure of $10-15 \mathrm{cmH}_{2} \mathrm{O}$ is necessary to obtain a collapse of the unplugged nostril valve to enable an accurate approximation of the Poes swing [12]. A comparison of SNIP with Poes during the same sniff manoeuvre (Sniff Poes) has been made in healthy adults, and in adult patients with neuromuscular disease [7] or chronic obstructive pulmonary disease (COPD) [14] but never in children with neuromuscular or lung disease. Because most neuromuscular and lung diseases exhibit a progressive course, they are generally less severe in children. In children, recurrent rhinitis and upper airway infections are common. Thus, the relationship between Sniff Poes and SNIP may be different in children than adults. Therefore, the aim of the present study was to compare SNIP with Sniff Poes in children with neuromuscular disease, severe scoliosis and cystic fibrosis (CF).

\section{MATERIALS AND METHODS \\ Patients}

The study protocol was approved by the institutional review board (Armand Trousseau Hospital, Paris, France), and informed consent was obtained from all the children and their parents.

The patients were recruited on a consecutive basis from the Armand Trousseau Hospital outpatient clinic. The patients belonged to three categories, neuromuscular disease $(n=78)$, thoracic scoliosis $(n=12)$ and CF $(n=23$; table 1$)$. None of the patients had obvious nasal obstruction or congestion, which was checked by the patient's ability to breathe through one nostril while the other was occluded (table 1).

\section{Measurements}

Poes was measured using a catheter mounted pressure transducer system (Gaeltec, Isle of Skye, UK) [15] inserted pernasally after careful, local unilateral anaesthesia (lidocaine 2\%; AstraZeneca, Rueil-Malmaison, France). Appropriate placement of the Poes transducer was assessed using a common method [16]. The plug used to obstruct the other nostril was a 13-mm eartip used for auditory evoked potentials (Nicolet Instruments Inc., Madison, WI, USA). It incorporated the distal $1-2 \mathrm{~cm}$ of a $90-\mathrm{cm}$ polyethylene catheter with a 2-mm internal diameter (Intersurgical Scientific Instruments, Oxford, UK). The other extremity of the catheter was connected to a differential pressure transducer (Validyne DP15; Validyne Engineering, Northridge, CA, USA), which was wired to a carrier demodulator (Validyne CD15; Validyne Engineering) and passed through an analogue-digital board to a computer which was running adequate software (Biopac Systems, Goleta, CA, USA). The absence of air leak around the eartip was ascertained by occluding the contralateral nostril during an inspiratory effort.

The sniffs manoeuvres were performed in a single session with the patient seated in front of the computer screen. The patient was instructed to perform short sharp sniffs with a closed mouth, starting from the end-expiratory volume after a quiet breath. Each sniff was associated by a strong verbal encouragement with visual feedback. At least 20 sniffs were performed, each separated by $30 \mathrm{~s}$, until a consistent value was reached [17]. Sniff Poes and SNIP represented the amplitudes of pressure changes, and were expressed in absolute values. For each patient, the highest sniff value was taken.

All of the patients were asked to perform at least three physician-accepted forced vital capacity (FVC) curves, and the curves with the highest FVC were used for the final analysis [18]. Results were expressed as a per cent of published values (\% pred). Height was calculated as the arm span for the patients with neuromuscular disease and scoliosis [19, 20].

In order for the present authors to validate their proceedure, SNIP was compared to Sniff Poes in eight healthy adults, mean age $28.5 \pm 5.6$ yrs, who were free of any known ear, nose and throat (ENT), respiratory or neurological disease. Mean Sniff

\section{TABLE 1 Patients' characteristics}

\begin{tabular}{|c|c|c|c|}
\hline Subjects $n$ & 78 & 12 & 23 \\
\hline Female/male $n$ & $20 / 58$ & $10 / 2$ & $13 / 10$ \\
\hline Weight kg & $42.2 \pm 3.7$ & $49.5 \pm 11.6$ & $38.3 \pm 9.7$ \\
\hline Height $\mathbf{c m}^{\#}$ & $146 \pm 4$ & $163 \pm 11$ & $150 \pm 10$ \\
\hline $\mathrm{FEV}_{1 / \mathrm{FVC}} \%$ pred & $107 \pm 29^{\prime}$ & $103 \pm 55^{+}$ & $75 \pm 17^{\S}$ \\
\hline Sniff Poes $\mathrm{cmH}_{2} \mathrm{O}$ & $49 \pm 4^{f}$ & $82 \pm 25$ & $93 \pm 29$ \\
\hline SNIP $\mathrm{cmH}_{2} \mathrm{O}$ & $41 \pm 4^{f}$ & $70 \pm 25$ & $66 \pm 29$ \\
\hline SNIP/Sniff Poes ratio & $0.83 \pm 0.17$ & $0.86 \pm 0.10$ & $0.72 \pm 0.13^{\# \#}$ \\
\hline
\end{tabular}


Poes was $93 \pm 27 \mathrm{cmH}_{2} \mathrm{O}$ and mean SNIP was $86 \pm 27 \mathrm{cmH}_{2} \mathrm{O}$. The SNIP/Sniff Poes ratio was 0.93 , which is comparable to a previously reported value (see supplementary material) [7].

\section{Statistical analysis}

The agreement between SNIP and Sniff Poes was assessed by the method of differences against the means, according to Bland and Altman [21]. The relationships between the SNIP/ Sniff $P$ oes ratio and age and spirometric data were assessed by linear regression analysis. For quantitative variables, comparisons between the patient groups were conducted using ANOVA. A p-value $<0.05$ was considered as significant.

\section{RESULTS}

\section{Patients}

The characteristics of the patients are represented in table 1 . In total, 42 neuromuscular patients had Duchenne muscular dystrophy, 14 patients had spinal muscular amytrophy and the remaining 22 had another congenital myopathy. Four patients (three patients with Duchenne muscular dystrophy and one patient with spinal muscular amyotrophy) required long-term nocturnal noninvasive positive pressure ventilation. FVC and forced expiratory volume in one second (FEV1) were markedly reduced in all the patient groups.

\section{Sniff Poes and SNIP values}

The Sniff Poes and SNIP values were significantly lower in the patients with neuromuscular disease compared to the patients with scoliosis and CF (table 1). The SNIP/Sniff Poes ratio was lower in patients with CF $(0.72 \pm 0.13)$ than in patients with neuromuscular disease $(0.83 \pm 0.17)$ or thoracic scoliosis $(0.86 \pm 0.10$; table 1$)$. Figure 1 represents the plots of the difference between Sniff Poes and SNIP against their mean for the three patient groups.

The mean difference between Sniff $P$ oes and SNIP was significantly greater in the patients with CF than in the other two groups. When choosing an arbitrary difference of $15 \mathrm{cmH}_{2} \mathrm{O}$ between Sniff Poes and SNIP, $17 \%$ of the patients with neuromuscular disease, $33 \%$ of the patients with thoracic scoliosis and $87 \%$ of the patients with CF had a Sniff Poes minus SNIP of $>15 \mathrm{cmH}_{2} \mathrm{O}$. The SNIP/Sniff $P$ oes ratio was not correlated with age or spirometric data, such as FVC, FEV1 and the FEV1/FVC ratio in any of the groups.

\section{DISCUSSION}

The present results show that SNIP may underestimate Sniff Poes in children with obstructive lung disease such as CF, but also in children with restrictive lung disease, such as neuromuscular disorders and scoliosis.

The SNIP manoeuvre has been shown to be both easy to perform and a reliable test of inspiratory muscle strength. Indeed, inspiratory muscle strength may be better reflected by SNIP than by PI,max [22], which is more difficult to perform, particularly in children [10]. During the sniff manoeuvre, the nasal valve located in the first $2.5 \mathrm{~cm}$ from the external orifice collapses when a critical trans-nasal pressure of $10-15 \mathrm{cmH}_{2} \mathrm{O}$ is reached [12, 23]. However, this value was measured in adults and may be different in children. In subjects without obstruction of the upper airways and normal lung and airway mechanics, there is only a small pressure gradient between the alveoli and extrathoracic airways located proximally to the point of collapse. As such, SNIP has proven to be a reliable estimate of Sniff $P_{\text {oes }}$ in healthy adults and in adults with neuromuscular disease [7]. However, in adults with COPD, SNIP may underestimate Sniff Poes [14]. This difference is explained by the short and dynamic character of the sniff manoeuvre. Indeed, the transmission of pressure changes from the alveoli to the mouth depends on a time constant, which is the product of airway resistance and upper airway compliance. This time constant is increased in patients with COPD, explaining the dampening of the pressure changes during a short manoeuvre such as a sniff. Similar observations have also been observed with the occlusion pressure, i.e. the pressure change measured at the mouth $0.1 \mathrm{~s}$ after the onset of the inspiration [24-26]. CF lung disease is characterised by progressive airway obstruction, due to a vicious circle of bronchial infection and inflammation. In agreement with the observation in patients with COPD, underestimation of Sniff Poes by SNIP was commonly observed in the CF patients included in the present study [14]. But as in adult patients with
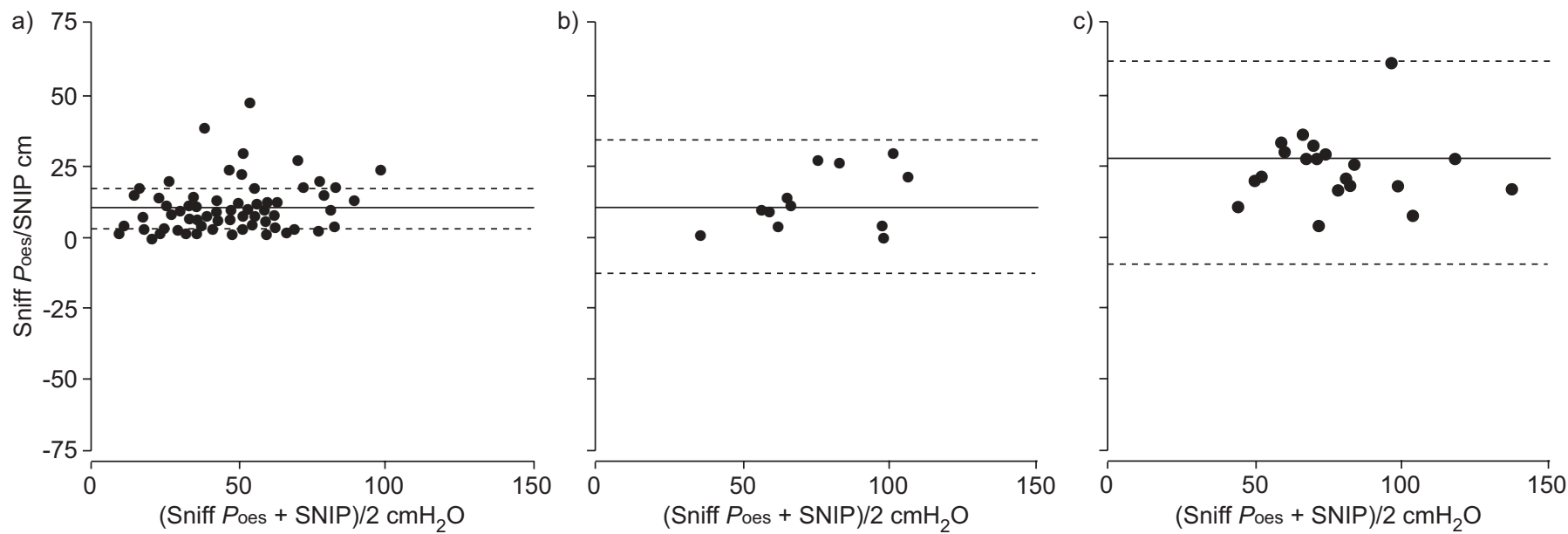

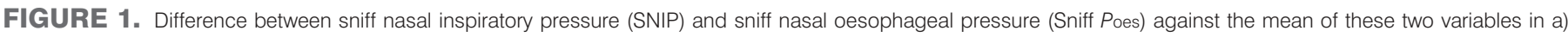
neuromuscular disease, b) thoracic scoliosis and c) cystic fibrosis patients. — : mean values; $\cdots \cdots \cdots \cdot \pm 2$ SD. 
COPD, the underestimation of Sniff $P_{\text {oes }}$ by SNIP in children with CF did not correlate with the degree of lower airway obstruction. One explanation may be that FEV1 and the FEV1/ FVC ratio reflect expiratory flow whereas the sniff is an inspiratory manoeuvre [14].

Obstruction of the upper airways may also contribute to the difference between SNIP and Sniff Poes. Nasal obstruction, due to nasal inflammation or polyposis, affects $32-65 \%$ of $\mathrm{CF}$ patients [27-29]. Indeed, a systematic clinical and radiological ENT evaluation has been performed in 75 patients from the Armand Trousseau Hospital and other CF clinics in Paris (France) and showed that $32 \%$ of the patients presented with nasal obstruction and $43 \%$ with nasal polyps [27]. In another French study, 39 (50\%) out of 78 CF patients aged 3-28 yrs presented with nasal polyps [28]. Even if nasal polyps are more common in adult CF patients [28], the current authors did not observe a correlation between the SNIP/Sniff Poes ratio and age in the CF population of the present study. For the patients with neuromuscular disease and thoracic scoliosis, the most plausible reason for the underestimation of Sniff $P$ oes by SNIP is nasal congestion and hypertrophy of the adenoids (and tonsils), which is very common in young children. The exclusion of the patients with obvious nasal obstruction or congestion seems to be insufficient to avoid this underestimation.

Although the present authors acknowledge that the inclusion of healthy children could have strengthened the results, there is an international agreement among paediatricians on the impossibility to perform invasive studies, such as the introduction of an oesophageal catheter, in healthy children $[30,31]$. For this reason, adult controls were evaluated whose results were comparable to those observed by ULDRY et al. [32].

In conclusion, the current results show that sniff nasal inspiratory pressure often underestimates the strength of inspiratory muscles in cystic fibrosis. Such an underestimation occurs more rarely in neuromuscular disorders and in thoracic scoliosis. As such, the sniff nasal inspiratory pressure may be useful as a screening test, normal values excluding inspiratory muscle weakness in children. But in the case of low values, the measurement of oesophageal pressure during a maximal sniff manoeuvre is warranted to rule out an erroneous diagnosis of inspiratory muscle weakness.

\section{REFERENCES}

1 Polkey MI, Green M, Moxham J. Measurement of respiratory muscle strength. Thorax 1995; 50: 1131-1135.

2 American Thoracic Society/European Respiratory Society, ATS/ERS statement on respiratory muscle testing. Am I Respir Crit Care Med 2002; 166: 518-624.

3 Aldrich TK, Spiro P. Maximal inspiratory pressure: does reproducibility indicate full effort? Thorax 1995; 50: 40-43.

4 Gaultier C, Zinman R. Maximal static pressures in healthy children. Respir Physiol Neurobiol 1983; 51: 45-61.

5 Wilson SH, Cooke NT, Edwards RH, Spiro SG. Predicted normal values for maximal respiratory pressures in caucasian adults and children. Thorax 1984; 39: 535-538.

6 Tomalak W, Pogorzelski A, Prusak J. Normal values for maximal static inspiratory and expiratory pressures in healthy children. Pediatr Pulmonol 2002; 34: 42-46.
7 Héritier F, Rahm F, Pasche P, Fitting JW. Sniff nasal pressure. A noninvasive assessment of inspiratory muscle strength. Am J Respir Crit Care Med 1994; 150: 1678-1683.

8 Stefanutti D, Fitting JW. Sniff nasal inspiratory pressure. Reference values in Caucasian children. Am J Respir Crit Care Med 1998; 159: 107-111.

9 Stefanutti D, Benoist MR, Scheinmann P, Chaussain M, Fitting JW. Usefulness of sniff nasal pressure in patients with neuromuscular or skeletal disorders. Am J Respir Crit Care Med 2000; 162: 1507-1511.

10 Rafferty GF, Leech S, Knight L, Moxham J, Greenough A. Sniff nasal inspiratory pressure in children. Pediatr Pulmonol 2000; 25: 468-475.

11 Prigent $\mathrm{H}$, Lejaille M, Falaize L, et al. Assessing inspiratory muscle strength by sniff nasal inspiratory pressure. Neurocrit Care 2004; 1: 475-478.

12 Haight JS, Cole P. The site and function of the nasal valve. Laryngoscope 1983; 93: 49-55.

13 Hart N, Polkey MI, Sharshar T, et al. Limitations of sniff nasal pressure in patients with severe neuromuscular disease. J Neurol Neurosurg Psychiatry 2003; 74: 1685-1687.

14 Uldry C, Janssens JP, de Muralt B, Fitting JW. Sniff nasal inspiratory pressure in patients with chronic obstructive pulmonary disease. Eur Respir J 1997; 10: 1292-1296.

15 Stell IM, Tompkins S, Lovell AT, Goldstone JC, Moxham J. An in vivo comparison of a catheter mounted pressure transducer system with conventional balloon catheters. Eur Respir J 1999; 13: 1158-1163.

16 Baydur A, Behrakis PK, Zin WA, Jaeger MJ, Milic-Emili J. A simple method for assessing the validity of the esophageal balloon technique. Am Rev Respir Dis 1982; 126: 788-791.

17 Lofaso F, Nicot F, Lejaille M, et al. Sniff nasal inspiratory pressure: what is the optimal number of sniffs? Eur Respir J 2006; 27: 980-982.

18 Arets HGM, Brackel HJL, van der Ent CK. Forced expiratory manoeuvres in children: do they meet ATS and ERS criteria for spirometry? Eur Respir J 2001; 18: 655-660.

19 Johnson BE, Westgate HD. Methods of predicting vital capacity in patients with thoracic scoliosis. J Bone Joint Surg Am 1970; 52: 1433-1439.

20 Miller F, Koreska J. Height measurement of patients with neuromuscular disease and contractures. Dev Med Child Neurol 1992; 34: 55-60.

21 Bland JM, Altman DG. Statistical methods for assessing agreement between two methods of clinical measurement. Lancet 1986; 1: 307-310.

22 Laroche CM, Mier AK, Moxham J, Green M. The value of sniff esophageal pressures in the assessment of global inspiratory muscle strength. Am Rev Respir Dis, 138: 598-603.

23 Bridger GP, Proctor DF. Maximum nasal inspiratory flow and nasal resistance. Ann Otol Rhinol Laryngol 1970; 79: 481-488.

24 Marazzini L, Cavestri R, Gori D, Gatti L, Longhini E. Diffference between mouth and esophageal occlusion pressure during $\mathrm{CO}_{2}$ rebreathing in chronic obstructive pulmonary disease. Am Rev Respir Dis 1978; 118: 1027-1033.

25 Murciano D, Aubier M, Bussi S, Derenne JP, Pariente R, Milic-Emili J. Comparison of esophageal, tracheal, and mouth occlusion pressure in patients with chronic 
obstructive pulmonary disease during acute respiratory failure. Am Rev Respir Dis 1982; 126: 837-841.

26 Elliott MW, Mulvey DA, Green M, Moxham J. An evaluation of P0.1 measured in mouth and oesophagus, during carbon dioxide rebreathing in COPD. Eur Respir J 1993; 6: 1055-1059.

27 Coste A, Gilain L, Roger G, et al. Endoscopic and CT-scan evaluation of rhinosinusitis in cystic fibrosis. Rhinology 1995; 33: 152-156.

28 Triglia JM, Belus JF, Dessi P, Noirclerc M, Cannon IM. Rhinosinusal manifestations of cystic fibrosis. Ann Otolaryngol Chir Cervicofac 1993; 110: 98-102.
29 Yung MW, Gould J, Upton GJ. Nasal polyposis in children with cystic fibrosis: a long-term follow-up study. Ann Otol Rhinol Laryngol 2002; 111: 1081-1086.

30 National Health and Medical Research Council (NHMRC). National Statement on Ethical Conduct in Research Involving Humans. Canberra, Commonwealth of Australia, 1999.

31 Royal College of Paediatricians and Child Health, Ethics Advisory Committee, Guidelines for ethical conduct of medical research involving children. Arch Dis Child 2002; 82: $177-182$

32 Uldry C, Fitting JW. Maximal values of sniff nasal inspiratory pressure in healthy subjects. Thorax 1995; 50: 371-375. 